\title{
ACRL in New Orleans ACRL programs at the ALA Annual Conference
}

\begin{abstract}
A LA's 125th Annual Conference was held June 22-28, 2006, in New Orleans. Approximately 17,000 librarians, library support staff, exhibitors, writers, educators, publishers, and special guests attended the conference. Ed. note: Thanks to the ACRL members who summarized programs to make this report possible.
\end{abstract}

\section{The emperor has no clothes}

The ACRL President's Program was exceptionally well attended. More than 650 conference attendees were welcomed by ACRL President Camila A. Alire and joined her in congratulating the 2006 ACRL division award winners. The program, "The Emperor Has No Clothes: Be it Resolved that Information Literacy

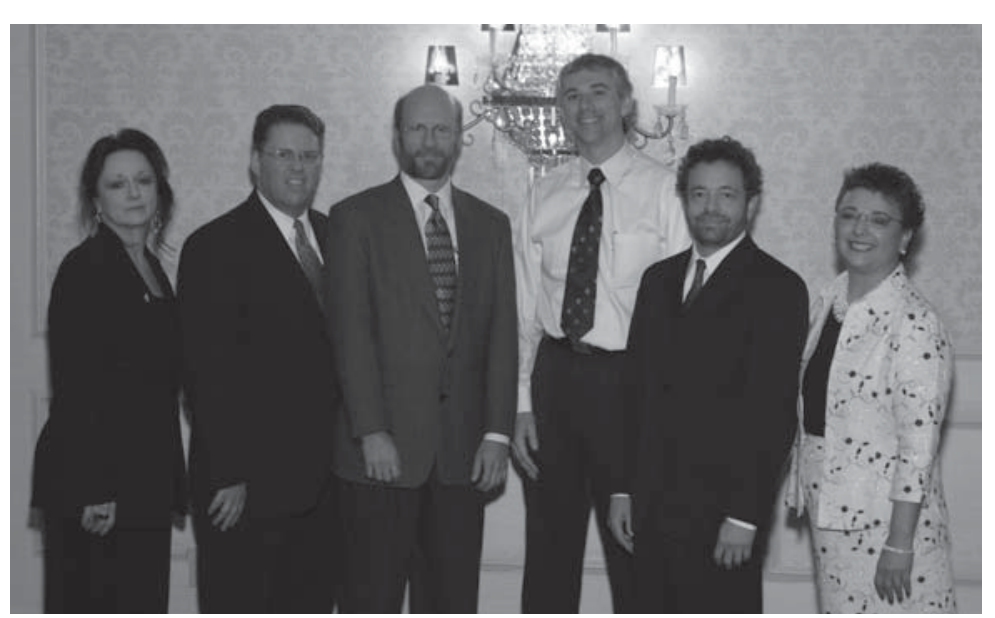

The 2006 President's Program speakers (left to right): Julie Todaro, Austin Community College; Moderator, Jim Neal, Columbia University; Jeffrey Rutenbeck, Champlain College; Gary Radford, Fairleigh Dickinson University; Stanley Wilder, University of Rochester; and 2005-06 ACRL President Camila Alire. lege) spoke against the resolution. Jeffrey Rutenbeck (director of digital media studies at the University of Denver) and Stanley Wilder (associate dean of the University of Rochester Library) spoke in support of the resolution. Jim Neal (vice president for information services and university librarian at Columbia University) moderated the debate.

Neal introduced the program by explaining that debates serve the purpose of provoking questions and testing assumptions about the value of our ideas. A strong resolution

statement is required, and certainly for this audience of librarians the idea that "information literacy is a fad and a waste of librarians' time and tale n t" was provocative. The debaters presented the affirmative and negative constructives is a Fad and Waste of Librarians' Time and Talent," was presented in formal debate style. The four debaters included two academic faculty members and two librarians. Gary P. Radford (professor of communication studies at Fairleigh Dickinson University) and Julie B. Todaro (ACRL president-elect and dean of library services at Austin Community Col- and rebuttals, and the program included five brief comic interludes. Attendees were given the opportunity to react to the debaters statements about information literacy, including the idea proposed by Wilder that a "fad-free teaching function" is needed instead of information literacy. Rutenback gave the audience something to consider when he 
suggested information literacy cannot be learned. Radford in his negative response to the resolution suggested there is a need to emphasize critical thinking and to encourage "skepticism, curiosity and imagination" in students. Todaro, using a comparison to the practice of medicine, highlighted the important curative and preventative aspects of information literacy and spoke convincingly about the need for librarians to continue this important work.

The comic interludes added a touch of fun and, in the end, not many minds were changed. Pre- and post-debate audience voting supported the importance of information literacy with a majority of attendees rejecting the resolution.-Elizabeth Henry, University of Missouri-Kansas City, henryel@umkc.edu

\section{Copyrights and licensing wrongs}

More than 200 people had the opportunity to hear two lively presentations focusing on "Copyrights and Licensing Wrongs: When Two Worlds Collide," the ACRL Copyright Committee program. Eric Slater (manager of copyright for the American Chemical Society's Publishing Division) began the program with a brief overview of the copyright law. He then discussed whether, in the online environment, copyright provides additional protection to copyright holders. The answer is no, although it may appear to be so. This is because more publishing entities have moved to a licensing model—and, in many cases, the licenses restrict activities that are permitted under copyright law - and contract law supersedes copyright law. Slater then discussed issues directly affecting licensing, including open access, creative commons, and institutional repositories.

Karen Hersey (retired Massachusetts Institute of Technology attorney and visiting professor at the Franklin Pierce Law Center) began her talk with an overview of the current and future state of copyright law. She discussed how three changes in the law: the Digital Millennium Copyright Act, the Sonny Bono Copyright Term Extension Act, and the TEACH Act all impact libraries and library users, primarily through the whittling away of fair use exemptions by banning reverse engineering, and the erosion of the public domain by adding an additional 20 years onto the duration of copyright. Hersey then took up the issue of copyright and licensing, discussing some of the limitations licenses have imposed upon libraries, which, in some cases, limit those uses for which the item was acquired in the first place.

Unfortunately, very little time remained for questions. However, attendees agreed that the content was useful, and that they look forward to future programs on copyright issues.-Becky Albitz, Pennsylvania State University, rsa4@psulias.psu.edu

\section{Plugging into student gadgets}

In a room set up for 200, more than 300 attendees crowded in to hear "Use What They Own-Go Where They Are: Plugging the Library into Student Gadgets and Habitats!" a University Library Section program.

Nancy Davenport (president of the Council on Library and Instruction Resources) presented an overview of our paradigm shift in libraries. We are living in a time of abundance, not scarcity, of information. "If it is not digital, it doesn't exist," is the current view of our students who want the library to be where they are, at their comfort level. Davenport spoke about our movement towards collective scholarship, e.g., Wikipedia. We need to "get over it and move on, if you find an error fix it."

Lynn O'Brien (director of academic instructional technology at Duke University) took Davenport's macro vision down to a micro vision, exploring Duke's programs with portable, personal technologies for education. Students are listening to old time radio shows recorded in the 1920s on their iPods, then doing their own productions of the shows and podcasting them on a Web site; students are completing Spanish oral comprehension exercises at their own pace using iPods to record their speech; 500 key terms for the anatomy of the human brain with text description, audio pronunciation, 
and brain images are optimized for iPod display; and a natural catastrophe course, an interdisciplinary service project, is using lectopia recordings of guest speakers and lectures, doing online quizzes in Blackboard, and audio journals from the service project are recorded with iPods - these are just a few of the technological advancements at Duke.

Six excellent poster sessions followed the program, which presented innovative techniques to reach students where they live and play using new technology or new approaches at other universities.-_Rita Bullard, Eastern Michigan University, rbullard@emich. $e d u$

\section{Beyond Katrina}

Wayne Parent, (associate dean of the College of Arts and Science and professor of political science at Louisiana State University) started off the Law and Political Science Section's program, "Beyond Katrina: Politics, Race and Law," with a discussion of the traditional divisions of Louisiana politics between the African American, Cajun, and Bible populations. Since all three were fairly equally balanced, the perceived attempt to rebuild New Orleans without its majority African American population would tilt the political balance of power in the state. Parent commented that the decline in the oil and gas industry was leading to the decline in corruption in the state. He thought that it would continue due to increased scrutiny.

Warren M. Billings (distinguished professor of history at the University of New Orleans) spoke of how a chance meeting with a member of the Louisiana Supreme Court secured the donation of its archives to the University of New Orleans. Previous custodians of the documents had ordered them by number, resulting in confusion as case numbering began anew each year. The need to order the archives and supervise students working with them led him to develop an expertise in Louisiana law in addition to his main field, colonial general assemblies.

Adolph Reed (professor of political science at the University of Pennsylvania) spoke of the need to study fields such as history, economics, and philosophy to understand politics, and called himself a "parasite off the works of historians." Reed advocated a broad view of politics saying, "market forces aren't the only thing." While much attention is being paid to New Orleans homeowners, he said, it seems that renters don't count any more.

All the speakers were in agreement on the failure of the federal government to assist Louisiana after Katrina, and the need to rebuild New Orleans. They commented that the recent election for mayor had been one that was free of both racial issues and corruption and had concentrated on the issues involved in rebuilding the city.

Discussion after the presentation centered on the difficulty of finding jobs in Louisiana today for those who are committed to remaining in the state and a robust dialog on the administration's failures in the region.-Catherine Doyle, Westfield State College,cdoyle@wsc.ma.edu

\section{The power of persuasion}

Robert Cialdini (professor at Arizona State University) a renowned expert on persuasion, presented his "principles of ethical influence" to an enthralled audience of more than 120 librarians. His workshop, cosponsored by the ACRL Presidential Task Force on Grassroots Advocacy and the University Libraries Section was entitled "The Power of Personal Persuasion: Advocating for the Academic Library Agenda from the Frontlines," and is a cornerstone of ACRL Past President Camila A. Alire's efforts to promote grassroots advocacy among frontline librarians by building knowledge, skills, and confidence.

Cialdini was an engaging and persuasive speaker, deftly combining 30 years of research and anecdotes to share his conclusions on what works and why. Research shows that people say "yes" based on how one presents without changing the content of the argument. He believes that librarians have a strong case to make for themselves on campus, but that reason and explanation are insufficient if presented poorly. 
There are six principles in all. Reciprocation is based on the universal belief that one must not take without giving in return, and that it is therefore best to be the first person to give service, information, or concessions. Scarcity is the idea that people want what they cannot have, so that it is important to highlight unique features, exclusive information, and genuine scarcity - and to emphasize what people might lose over what they might gain. Authority refers to the notion that the characteristics of knowledge and trustworthiness lead to credibility. To establish credibility, experts must show credentials and relevant knowledge and professionalism-they must also share weak arguments before making strong arguments. Consistency occurs after a person takes a stance (ideally one that is active, public, and voluntary) that is consistent with the argument. Consensus is the power of conformity: people are influenced by testimonials and successes from people like them. Liking means that people prefer to say yes to those they know and like, which includes uncovering real similarities, making genuine compliments, and finding opportunities to cooperate.

Cialdini guaranteed that his principles of persuasion would be successful, not only at work, but in the community and with friends and family. He warned of bunglers, who fumble away opportunities, and smugglers, who use the principles dishonestly; and instead recommended acting as sleuths, who uncover the six principles and bring them to the mind of the person they are trying to influence. As a memento, Cialdini gave all participants a laminated plastic card listing the six principles.

Julie B. Todaro (ACRL president elect and dean of library services at Austin Community College), who helped plan the event, led an activity in which participants uncovered their own spheres of influence as an introduction to the "Power of Personal Persuasion Toolkit" she designed specifically for frontline librarians. She encouraged everyone to try some techniques and then to come to the ACRL National Conference in Baltimore to share their experiences. The toolkit will be mailed to every ACRL member.-Mark Emmons, University of New Mexico, emmonds@umn.edu

\section{HBCUs and libraries}

The African American Studies Librarians Section (AFAS) sponsored a session titled "HBCUs and Libraries: Preserving and Strengthening Bonds." Cosponsors for the session included the Black Caucus of the American Library Association (BCALA), the College Libraries Section (CLS), and the University Libraries Section (ULS).

Thomas Weissinger (University of Illinois, chair of AFAS Program Planning Committee) introduced the speakers and provided a historical backdrop on Historically Black Colleges and Universities (HBCU), Black studies programs, and the "changing role for Black studies librarians."

The session speakers focused on the history and work of the HBCU Library Alliance-a collaboration of 93 librarians from 103 libraries across the nation.

Janice Franklin (Alabama State University), Emma Bradford Perry (Southern University-Baton Rouge), and Ira Revels (Cornell University) were the speakers representing the HBCU Library Alliance. Franklin spoke about the goals and challenges that include preserving and conserving the treasures housed in HBCUs. She spoke of the support that SOLINET provides that has created the Alliance of Learners to tackle opportunities and challenges now and in the future. Perry spoke about the leadership challenges for HBCUs and how funding from the Mellon Foundation allowed the alliance to develop a leadership institute retreat, a pilot program for ten members of the alliance. She stressed the need for "relationships, relationships, relationships" to encourage new ideas and collaborations, promote publishing, extend mentoring beyond the institute, and provide travel funding. Revels spoke about the digital project she manages for the alliance and its partners that include Cornell University, SOLINET, and the Woodruff Library at Atlanta University. The partnership provides equip- 
ment, training, and quality control for alliance member institutions to identify collections and resources for digitization.

Brenda Square (Amistad Research Center at Tulane University in New Orleans) concluded the program by emphasizing that although Amistad is not housed on an HBCU campus, it houses numerous collections on the founding of HBCUs all over the nation. She spoke about the importance of the collection to the history of education and the need for our continued support, collaboration, and cooperation with the missions of HBCUs and how it is mirrored in the founding of the Amistad Research Center.-Rebecca Hankins, Texas A\&M University, rhankins@ lib-gw.tamu.edu

\section{Leadership for learning}

The Instruction Section (IS) sponsored program, "Leadership for Learning: Building a Culture of Teaching in Academic Libraries," opened with an emotional reminder from Mary Jane Petrowski (ACRL associate director), the recipient of the Miriam Dudley Instruction Librarian Award, "Fail early and often in order to succeed sooner."

In the presentation "Taking Teaching Seriously: Fostering a Climate of Instructional Development," Jennifer Meta Robinson (Indiana University-Bloomington) offered the anecdote of an instructional opportunity generated by a student journalism group that organized a relief effort in New Orleans as a way to "move the campus climate towards teaching by moving the conversations into the public realm." Librarians can foster common ground by engaging in partnerships with faculty members, learning the landscape of the literature on teaching, offering knowledge about information architecture and organization, and by infiltrating existing initiatives on teaching.

James L. Mullins (Purdue University) proposed the question, "What are the challenges library administrators perceive as the difficulties in information literacy?" Through the personal experience of missing valid information for an honors thesis, he realized that, "Today's complexities add a new layer to the information literacy commitment."

Patricia B. Yocum's (University of Michigan) presentation delivered an overview of the University of Michigan's Library Instructor College program, which acknowledges "teaching is changing, even as we speak." She reflected that the most popular session includes an emphasis on the instructional design of programming for adult learning styles. The program's key to success is that it is peer designed, run, and delivered.

Susan Carol Curzon (California State University-Northridge) highlighted the construction of a sustainable teaching culture within libraries through several avenues, including a reminder that culture begins with values; planning provides the framework for success; teaching librarians require administrative and physical resource support; good teaching necessitates reward systems through promotion and tenure; "Never mistake motion for action"; ask the question, "Are we a prisoner of our own assumptions?"; and finally, assess, assess, assess.

The program was followed by a poster session.-Merinda Hensley, University of Illinois Urbana-Champaign, mbensle1@uiuc.edu

\section{Big ideas, small staff}

A can-do attitude prevailed at the College Libraries Section program, "Big Ideas, Small Staff: Successful Tactics for College Librarians." A near-capacity crowd of about 275 attendees was on hand to hear success stories from seven college librarians with cutting edge ideas that they were able to bring to reality using the resources of their small institutions. The program's goal was to demonstrate that college libraries can and do provide the same kinds of exciting new services to their students and faculty that our colleagues in large libraries do, once they find ways of overcoming staffing and budget constraints. "Like a cafeteria of good ideas," said one librarian. Some of those good ideas included using cost-free open source software (Pirate Source) to develop a portal, providing paid internships to graduating seniors 


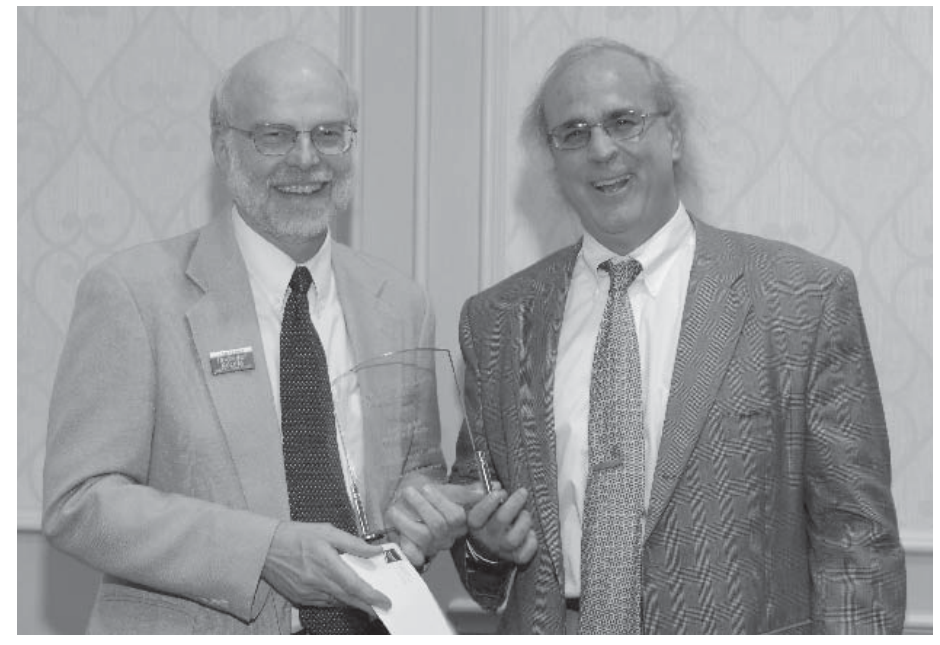

ACRL's 2006 Academic/Research Librarian of the Year Ray English with Bob Nardini, senior vice president of YBP Library Services.

interested in librarianship, using students to launch a digitization project, creating a peer tutor basic research program, sharing programming with a local public library, including information literacy into key discipline courses, transforming them from three- to four-credit courses, and marketing special collections to promote the college and library, as well as enhance student research. As persons attending commented: "Seeing what others are up to inspired me to think about what I might do at my library," and "Great ideas. I wish I had some of them before starting down other paths." A complete list of speakers and topics is available on the CLS Web site at www.ala.org/ala/acrlbucket/cls/ acrlpresentation/2006annualPresentation. htm-Dena Hutto, Reed College, dena. butto@reed.edu, and Alice Babr, Salisbury University, abbabr@salisbury.edu

\section{Publish, don't perish}

The program "Publish, Don't Perish: Helpful Hints for Authors" was cosponsored by the ACRL New Publications Advisory Board and the ACRL College Library Section Research Committee. The speakers included Tony (Charles A.) Schwartz (Florida International University), Marie L. Radford (Rutgers University), and Patricia Glass Schuman (NealSchuman Publishers).

Schwartz described some of the ways librarians can identify and refine a worthy topic for research, for example, a subject thought to be complex is actually simple or a subject previously thought to be simple is actually complex; and something that is generally considered to be good is bad or vice versa. He noted that when faced with the requirement to publish to meet tenure requirements, a librarian would be well advised to select a subject area they know well and to focus on a research question for which they already know the outcome and the conclusions. He suggested that only after meeting the requirement for publication should a librarian embark upon research in an unfamiliar area.

Radford's presentation included tips on how to increase "writing productivity and enjoyment," including write in short, regular sessions; solicit and welcome suggestions from others; work to your interests; and develop the habit of using a writing notebook to save ideas. She also emphasized the importance of time management, using Stephen Covey's time management matrix to illustrate the need to spend time in planning and writing to lessen time spent "writing on deadline" in a crisis mode.

Speaking from the perspective of the book publisher, Schuman recommended that writers begin by determining the purpose the book will serve, the audience for the book, and why the book is needed. Schuman offered a list of "important topics for today's library publishers," including "acquisitions, management, marketing and public relations, and digital/virtual reference," among others.-Jan Kemp, Lamar University, jan. kemp@lamar.edu

\section{Cultural studies}

At the 2006 ALA Annual Conference the Literatures in English Section of ACRL presented the program "Cultural Studies in the Academic Library." The program, attended by nearly sixty people, sought to examine how 
academic librarians are supporting cultural studies (CS) scholars, whose interests range into the social sciences.

The moderator, Rob Melton of the University of California (UC)-San Diego introduced the panel by noting that CS has an increasing presence in the academy, though defining the field itself is a real challenge.

The first speaker, Professor Joel Dinerstein of the Tulane University English Department offered an overview of CS and emphasized the left-wing orientation of CS and its interest in the rights of the oppressed. He also asserted that popular culture and its social role are of more interest to CS scholars than the aesthetic qualities of high art.

The second speaker, Jane Faulkner of UC Santa Barbara, presented the results of a survey she conducted (with fellow librarian Melton) of English professors in the UC system who have some involvement with CS. The survey identified seminal texts and major authors and publishers in CS, but also revealed that CS scholars find traditional research tools inadequate for their interdisciplinary approach.

Finally, Mark Szarko of the University of Washington-Bothell shared his experiences in building a collection for the M. A. in Cultural Studies Program at his institution. In his presentation, "Defining Culture in the Stacks: Collection Development in Cultural Studies," Szarko stated that CS is not a discipline but rather as an interdisciplinary approach to the study of culture. Also, Szarko argued that CS is more than merely an academic discipline; it is also a form of political action that changes power hierarchies inscribed in cultural texts and institutions,

The program ended with a discussion involving members of the audience and the panelists. Professor Dinerstein agreed with a criticism of CS elitist language. Other comments recognized the inherent contradiction between the interdisciplinarity of CS and calls for research resources exclusively dedicated to CS. Finally, attendees thanked the organizers for distributing a CS bibliography and the UC faculty survey.-Sophie Lesinska, University of Southern California, lesinska@usc.edu

\section{Reimagineering special collections}

At the Rare Books and Manuscripts Section program, an administrator, an architect, and a librarian presented three perspectives on "Reimagineering Special Collections: Building Designs and Considerations for the 21st Century."

Jeanne Hammer (assistant director for Finance and Administration at North Carolina State University) stressed the importance of partnering with builders. She encouraged librarians to visit the construction site regularly, ask questions, and talk with the construction manager often. More formal communications should include progress meetings at least twice per month. Her general principles were, be flexible and adapt, fill vacuums, include a budget reserve of at least 5 percent, and hope for the best, but plan for the worst.

Janette Blackburn (senior associate at Shepley Bulfinch Richardson and Abbott) identified these current trends in special collections architecture: the need for expanded access and visibility, a rising need for flexible space, more varied collection formats, and new building technologies. Event and exhibit spaces are growing in importance. Architects are paying increasing attention to environmental issues, such as sustainable design and interior air quality, and using more sophisticated building project management techniques, such as building commissioning and life-cycle cost analysis. Overall, architects are increasingly integrating the design, mechanics, and construction of the building.

Pat Bozeman (head of special collections at the University of Houston) described the renovation of the M. D. Anderson Library. With the construction of a new wing, special collections moved from the library's top floors to the much more accessible second floor. Other improvements include improved climate control, new exhibit areas, proper shelving for the collections, large and flexible staff work areas, space for class presentations, and tighter security overall. Bozeman's slides vividly showed how the renovation improved the space. She emphasized that staff involve- 
ment throughout the planning and construction projects was crucial._Margaret Nichols, Cornell University,mnr1@cornell.edu

\section{Privacy and technology}

The ACRL Ethics Committee sponsored "Privacy and Technology in Libraries: Ethical Challenges and Responses," a presentation featuring Naomi Lederer (reference librarian at Colorado State University).

Librarians are particularly sensitive to the potential threats to privacy posed by the use of technology to find and use information. Lederer carefully set the stage for the audience by providing detailed background information about the concept of individual privacy. Although 48 states have laws on some aspect of privacy, it is not mentioned in the Constitution. She also observed that although ALA endorses the concept of patron privacy, there are currently no professional sanctions or fines for libraries or librarians that disregard privacy protection, although enforcement of the ALA Code of Ethics is under discussion by the Committee on Professional Ethics.

Lederer asserted that there is potential for misuse of the information that libraries and vendors collect as a matter of course. Database searches, table of contents searches, e-mail and chat reference exchanges are all amenable to capture and are used within libraries to assess services and collections. Vendors likewise collect information that allows them to focus and refine their products and services. The most troubling aspect about this wealth of information is that it could be used to target individuals rather than for planning and decision making.

For those who took Lederer's observation that "you already have zero privacy, so get over it" to heart, the program provided plenty of food for thought. College students in particular seem eager to share personal information about themselves on the Web, as evidenced by the popularity of sites such as MySpace. She concluded that one of the greatest services academic librarians can perform for their patrons is to continually educate them to the fact that the Web is not private.-Lori Phillips, University of Wyoming, lphil@uwyo.edu

\section{Immersion}

The Institute for Information Literacy sponsored "Model Programs from the Immersion Experience: Successes and Challenges." A panel of four faculty and alumni practitioners from the ACRL Immersion Program discussed the challenges of being leaders for instructional and institutional transformation. Poster sessions highlighted promoting information literacy as a community project of cooperation, collaboration, and communication at a range of institutions from small colleges to large universities.

Susan Avery (University of Illinois) described the challenge of providing instruction on a large scale with a staff comprised of mostly nonprofessional graduate assistants. Encouraging graduate students to think like teachers required a paradigm shift that created a positive environment of flexibility and experimentation.

Wendy Holliday (Utah State University) related the value of risk-taking for creativity and innovation that resulted in information literacy integration with a freshmen writing program. Librarians learned to take a chance and found success in the face of skepticism.

John Holmes (University of Washington) articulated a vision for information literacy that transcends teaching in libraries done by librarians. The UWired program successfully reaches students with an information literacy tutorial that faculty can customize to fit their course learning objectives, but the vision for instruction that transcends libraries requires ongoing development and progress that takes the form of a learning commons in collaboration with librarians, faculty, technology staff, and writing tutors.

Joan Weber (Yakima Valley Community College) discussed the formation of faculty and administrative partnerships through grantfunded activity. Librarians took the initiative to invite faculty participation in information literacy learning experiences that became partnerships in the classroom and curriculum planning. Targeting one faculty partner can open doors to multiple partners. 
Oklahoma State University, Ohio University, Manatee Community College, Trinity University, University of Texas-Arlington, Auburn University, and Hampden-Sydney College were represented in the poster sessions.-Elaine Reeves, Kettering University, ereeves@kettering.edu

\section{Grant writing}

The Education and Behavioral Sciences Section presented "Shaking the Money Tree: Grant Writing for Librarians." Elaina Norlin, (Institute of Museum and Library Services) and Tom Phelps (National Endowment for the Humanities) provided the agency perspective on the grant-writing process and Marcia Keyser (Drake University) provided the applicant librarian's perspective.

Norlin gave the audience valuable tips for writing "great" grant proposals. She covered the basics of meeting deadlines, understanding the guidelines, proofreading, and revision, and she emphasized the importance of identifying a problem that you are trying to solve along with a potential solution that a funding agency might support. "Funding programs are extremely competitive and the key is to convince the funding agency that you know what is needed to solve your problem."

Tom Phelps described the grant-writing process as matching the project with the correct funding agency and then completing the application. An endless number of government, private, and corporate funding sources exist as well as databases and directories that provide detailed information on them. He said to remember to establish your timeline to fit the source's deadline, and pay attention to the agency's criteria. Phelps's strategies for success include building a team and planning in advance. Some common pitfalls he identified are a lack of organization and emotional pleading.

Reflecting on her successful grant-writing experience, Keyser advised applicants to get to know the different offices and departments at their universities that provide grant-writing support and stressed to never assume that grant writing is a one-person show. Like
Phelps, Keyser asserted that with funding sources it is important to match the correct agency with the project. "Don't be afraid to think big with agencies, such as IMLS and $\mathrm{NEH}$, or to think small. There are several local agencies that want to support library or educational projects, too."

The PowerPoint presentations and handouts from the program are available at www. ala.org/ebss/shakingthemoneytree._Lisa Romero, University of Illinois Urbana Champaign,l-romero@uiuc.edu

\section{Campus diversity}

The Racial and Ethnic Diversity Committee sponsored a panel presentation that addressed ways in which academic libraries are positively affecting diversity on campus.

Scott Walter (University of Kansas) outlined a program piloted at Washington State University in which the library partnered with the Multicultural Student Center to recruit and retain students of color. The program includes an information literacy workshop used in the center's peer mentor program, information literacy workshops to be included in the center's regular rotation of academic support programs, and a description of library services for inclusion in the center's handbook.

Karen Downing (University of Michigan) presented the outcomes of the Peer Information Counseling Program (PIC), which recruits students from diverse backgrounds to serve as peer advisors. The program addresses graduation rate disparities among students from different racial and ethnic groups and the diversity climate on campus. It also addresses the need to represent different racial and ethnic groups on the reference desk. The success of the program is evidenced by the high graduation rate of PIC students and by the transformation of the library as a "go-to" place and partner when new diversity initiatives are undertaken on campus.

Polly Weiss (Duke University) spoke about a model, the diversity working group, which focuses on creating an inclusive work environment. The library at Duke pioneered the first diversity working group in 1998. 


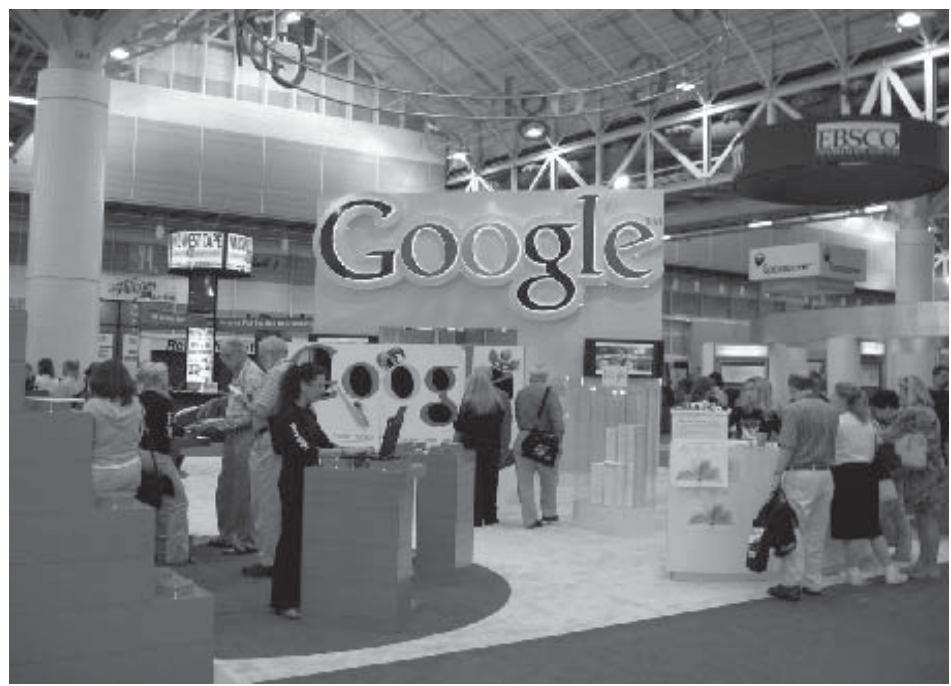

Attendees had the opportunity to learn about products and meet with 750 vendors on the exhibit floor during the conference.

Diversity working groups bring employees and managers together to assess workplace climate, provide education, and consult with library leaders. The success of the model is its adaptability; eleven additional diversity working groups across Duke have been organized using this model.

All three panelists underscored the importance of moving beyond recruitment to retention and full collaboration. The programs they discussed have contributed greatly to this change.-Natalie Sommerville, Duke University, natalie.sommerville@duke.edu

\section{Vanilla collections}

Two hundred librarians attended the ACRL Intellectual Freedom Committee's program, "Vanilla Collections: Have Alternative Viewpoints Disappeared from Academic Libraries?" A spirited debate on the question of whether academic collections adequately represent diverse viewpoints on controversial subjects ensued. Three speakers addressed the question: Charles Willett (Counterpoise, an alternative press distributor); Bob Nardini (senior vice president and head bibliographer at YBP Library Services); and Bart Harloe (university librarian at St. Lawrence University).

Willett gave a short review of library collections over the past 30 years, arguing that alternative presses have always been underrepresented. Even today, many subjects remain "beyond the pale," including both rightand left-wing viewpoints. He recognized that librarians with collection responsibilities are guided by curricular needs, but advised them to "bend the rules, stretch as much as you can" to include materials that otherwise might not be represented.

Nardini responded by describing studies about the effect of approval plans, which have been criticized for leading to homogenous collections. In one study, libraries using approval plans selected many unique, small press books, but when firm orders were subsequently placed, there was more overlap in the selected books. Nardini also contended that there are good business reasons for vendors to offer alternative and small press works.

Harloe described the browsing collection at St. Lawrence University that includes many titles from alternative presses. This small collection of 500 titles accounts for approximately 5 percent of their total circulation. Harloe also cited another study indicating that 70 percent of the resources held by the Connect New York consortium are held by only one library. He added that while approval plans may inadvertently limit librarians' choices, they are sometimes the only way small schools can acquire books they need.

The Q\&A session that followed highlighted the commitment of librarians to collect materials from a wide spectrum of viewpoints, even when they disagree with the views expressed.-Walter Stine, Fenway Libraries Online, stine@o.org

\section{Interdisciplinary information literacy}

What does information literacy look like in interdisciplinary fields of study? How can the Information Literacy (IL) standards be adapted for multiple audiences? These are some questions panelists and attendees explored during 
the Women's Studies Section Annual Program, "Doing Information Literacy Differently: The View from Interdisciplinary Studies."

Tiffini Travis (librarian at California State University-Long Beach) described the content, goals, and assessment of a six-week, modulebased tutorial for Black Studies faculty that helps faculty integrate IL into their courses. As a result of the tutorial, Travis saw an increase in the demand for instruction and collaboration between faculty and librarians. Travis advised those beginning similar endeavors to do focus group analysis, hire a Web designer, provide space for assignment revision, have faculty develop their own IL rubrics, and publish the results of the work.

Sara Heitshu (University of Arizona's American Indian Studies [AIS] librarian) spoke about her experiences incorporating IL concepts into library instruction linked to graduate courses. Heitshu gave a rich overview of the development and epistemology of AIS, and the specific ways this affects how she teaches and supports student research. Two examples of this are sharing information about her genealogy and the history of her name, and placing the concept of controlled vocabulary within the context of "naming" customs.

The final panelist, Sherri Barnes, discussed her undergraduate interdisciplinary course at the University of California-Santa Barbara, and shared several examples of how she engages students with broad aspects of research. These include illustrating the role professors and librarians play in the creation of information, discussing universality of citation, and asking students to think about agency in the publication process. Barnes emphasized that instruction in interdisciplinary fields provides opportunities for discussing IL concepts because the comparison of ideas and resources in multiple disciplines occurs naturally.-Heather Tompkins, Carleton College, btompkin@carleton.edu

\section{Preserving New Orleans}

Sixty-three people gathered to hear the timely and affecting presentation "Preserving New Orleans: The Fate of Media Collections in the
Wake of Katrina," by people whose responsibilities involved the care and preservation of sensitive media collections before, during, and after the recent disaster.

This Arts conference program was organized and moderated by Howard Besser (professor of cinema studies at New York University's Tisch School of the Arts and director of Moving Image Archiving and Preservation) and by graduate student Kara van Malssen. Besser opened with photographs he took in the hurricane's aftermath, explaining that his slides could not really capture the cumulative tragedy of block after block of devastation. He foreshadowed the theme of presenters that followed: most disaster plans assume that those who care for collections will be able to re-enter their workspaces within a few days and that power and communications will be re-established quickly. The disabled infrastructure in New Orleans immediately post-Katrina disabused everyone of this assumption.

Bruce Boyd Raeburn (curator of the Hogan Jazz Archive) presented "Hurricane Katrina: A Disaster in Retrospect." His was both a personal and professional account of the Katrina experience, which included recounting his evacuation to relatives in Oakland, California, and dealing with the recovery service, Belfor, upon return. He showed before and after photos of the workspaces and the building in which the archive is housed.

Raeburn also talked about the fate of private collections, using the Danny Barker collection as an example. This was a collection of jazz photos and ephemera for which he had been negotiating before the hurricane. Had the collection been donated to the archive (which suffered minimal damage) years before, it would have been safe. Instead, it was largely destroyed in the Barker home. What remains is now in the archive and is slowly being salvaged.

Alfred Lemmon (director of the Williams Research Center at the Historic New Orleans Collection [HNOC]) talked about HNOC's disaster preparations. HNOC had what was believed to be an adequate plan, including its 
disaster carts, "glow tabs" on priority collections, laying absorbent "snakes" in front of doors to prevent water flowing into vaults, and custom precut plywood for windows. During this storm with its unprecedented destruction, they realized that their disaster plan-like most in the city-was inadequate. Lemmon emphasized especially that there was not enough planning for communications. No one predicted that landlines, though damaged, would prove marginally more reliable than cell phones, which were largely useless. Lemmon described the evacuation of priority materials to Virginia, and how his institution's disaster plan has been revised since Katrina to include more extensive alternative communications scenarios.

Greg Lambousy (director of collections at Louisiana State Museum) presented, "The Louisiana State Museum, Hurricane Katrina, and the New Orleans Mint." Lambousy talked about the Louisiana State Museum's efforts to recover from losing 60 percent of the copper roof of the New Orleans Mint, which housed the majority of the museum's collections, including its library and archive. Lambousy also discussed the necessity of anticipating local transportation problems, protecting buildings rendered insecure by damage, the difficulty of contacting and reassembling staff, communications breakdowns, and the importance of establishing cooperative disaster-planning relationships with other institutions.

Kara van Malssen (researcher at New York University) pulled together what curators and archivists learned in "Post-Katrina Lessons for Mixed Media Collections." This summary of some of the most important lessons learned by institutions and individuals in New Orleans included the effectiveness of adequate disaster plans, external recovery services, the fate of private collections, and the risk of cultural collapse. These two latter topics address the poignant situation faced by individual artists and by the City of New Orleans as a cultural entity.

Artists habitually guard their creations as their personal expressions and are loathe to cede control to a museum or archive that will limit their access to and interaction with their own work. The resulting loss of cultural wealth in the wake of Katrina is causing at least some artists and collectors to rethink this relationship. The Barker collection of irreplaceable local jazz ephemera, photographs, etc. is one case in point.

The Hogan Jazz Archive, largely undamaged due to its felicitous third-floor location and knowledgeable disaster-ready staff, was engaged in active negotiations to acquire this collection, which was stored in garbage bags in the Barker house at the time of the storm. After significant flooding and a month without electricity, much of the Barker material was beyond saving. Local filmmakers have been devastated, as well—sadly, at least one committed suicide after the total loss of his latest project. Some survivors are reconsidering the better protection that a relationship with an institution might afford.

The cultural treasures of New Orleans are not only the nation's treasures, they are that city's unique heritage. So much of the city's media and its tradition of music, passed down through families and swapped by local musicians, are more fragile than we ever imagined. They need a home base of artists residing in the city, individual vision, local mentors, and dedicated professionals_-such as the participants in this program-to collect and preserve these artifacts of a unique place and its people.-Shannon Van Kirk, CalPoly University, ACRL/Arts Section,vankirk@calpoly.edu

\section{Immigration, ethnicities and historical research in New Orleans}

Multicultural roots form the core of New Orleans' identity. The panel of speakers for the Western European Studies Section program, including John Magill (Historic New Orleans Collection), Wilbur Meneray (Tulane University Library Special Collections), and Emily Clark (Tulane University History Department), explored the historical background and impact of immigration on New Orleans.

(continued on page 492) 
to hear from their librarians about the situation. There will be time for general audience discussion and a brief overview of the CAO research study.

\section{"From the Inside" column in C\&RL News}

You probably know at least one academic librarian who changed fields and is now working in another area of higher education. I think we can learn a great deal from higher education administrators who know libraries. To this end I am editing a series of columns for CERL News written by higher education administrators from all types of offices, who are former academic librarians. I will ask them to share their insights on how librarians can tell our story in terms our academic administrators will understand, and how ACRL members can communicate their value.

Questions I am asking include: From your "outsider's" point of view, what is the value of an academic library? How do you see academic library/librarians contributing to the success of your students and faculty? Can you talk about how librarians can best express their need for resources for the library? Which arguments are particularly effective?

I am very encouraged by the quality of the work to date and the response from ACRL members when I've discussed my presidential focus. If we can turn the answers to my questions about value into concise, yet powerful messages for our advocacy efforts, librarians will have the power to communicate the value of libraries, and we will be recognized for our contributions to learning and scholarship.

\section{Notes}

1. Oxford English Dictionary, dictionary. oed.com/.

2. Thomas Hobbes, Leviathan, 1651. Ed. Michael Oakeshott (Oxford: Blackwell, 1960): 57.

3. Leigh Estabrook, Interim Report, 2006.

4. Committee members include John Budd, Mary Carr, John Collins, Sally Kalin, Michael LaCroix (co-chair), Loretta Parham, Celia Rabinowitz, and Lisa Stillwell (co-chair).

( ACRL in New Orleans, cont. from page 484)

Each speaker drew upon his or her extensive use of local historic resources to study the ethnic groups that make up the fabric of New Orleans. The program extended principally to European immigration and to those ethnic groups from Europe and Africa that have joined with immigrants from the Caribbean, Latin America, Asia, and other parts of the world in helping to form the unique society of New Orleans and surrounding areas.

Magill focused on the British influence, one of the West European influences one does not so often associate with French New Orleans. The English and Scottish were very much a part of the city's financial community during its golden days. Meneray focused upon the settlement patterns, interethnic diversity, and the impact of the Civil War upon the immigrant population. Irish, Sicilian, and Jewish immigration formed part of this history.
Clark described her research on the period from 1700 to 1810 , using archival resources to reconstruct the experience of the largest group of immigrants during this period: people of African descent, including Creole African Americans and free people of color. Although published scholarship on these early New Orleanians is still relatively sparse, the archival sources bearing witness to their arrival and lives are especially rich and were left relatively unscathed by Katrina. Details that emerge from these records about family, religion, and economic networks suggest new ways to "see" the iconic architecture of the French Quarter.

For more information and bibliography on ethnic groups in New Orleans, see the program Web site at www.lib.byu.edu /estu/wess/2006program.html._Barbara Walden, University of Wisconsin-Madison, bwalden@library.wisc.edu $\mathbf{z}$ 